Editorial

\title{
Editorial: Is There a New Climate Politics?
}

\author{
Anna R. Davies ${ }^{1, *}$, Vanesa Castán Broto ${ }^{2}$ and Stephan Hügel ${ }^{1}$ \\ ${ }^{1}$ Department of Geography, Trinity College Dublin, Dublin 2, Ireland; E-Mails: daviesa@tcd.ie (A.R.D.), shugel@tcd.ie (S.H.) \\ 2 Urban Institute, University of Sheffield, Sheffield, S1 4DP, UK; E-Mail: v.castanbroto@sheffield.ac.uk \\ * Corresponding author
}

Submitted: 2 April 2021 | Published: 28 April 2021

\begin{abstract}
Addressing climate change globally requires significant transformations of production and consumption systems. The language around climate action has shifted tangibly over the last five years to reflect this. Indeed, thousands of local governments, national governments, universities and scientists have declared a climate emergency. Some commentators argue that the emergency framing conveys a new and more appropriate level of urgency needed to respond to climate challenges; to create a social tipping point in the fight against climate change. Others are concerned to move on from such emergency rhetoric to urgent action. Beyond emergency declarations, new spaces of, and places for, engagement with climate change are emerging. The public square, the exhibition hall, the law courts, and the investors' forum are just some of the arenas where climate change politics are now being negotiated. Emergent governing mechanisms are being utilised, from citizens' assemblies to ecocide lawsuits. New social movements from Extinction Rebellion to Fridays For Future demonstrate heightened concern and willingness to undertake civil disobedience and protest against climate inaction. Yet questions remain which are addressed in this thematic issue: Are these discourses and spaces of engagement manifestations of a radical new climate politics? And if these are new climate politics, do they mark a shift of gear in current discourses with the potential to effect transformative climate action and support a just transition to a decarbonised world?
\end{abstract}

\section{Keywords}

climate assemblies; climate change; climate emergency; climate politics; Green New Deal; just transition; youth movements

Issue

This editorial is part of the issue "Is There a New Climate Politics? Emergency, Engagement and Justice" edited by Anna R. Davies (Trinity College Dublin, Ireland), Stephan Hügel (Trinity College Dublin, Ireland) and Vanesa Castán Broto (University of Sheffield, UK).

(C) 2021 by the authors; licensee Cogitatio (Lisbon, Portugal). This editorial is licensed under a Creative Commons Attribution 4.0 International License (CC BY).

\section{Introduction}

Climate politics may be entering a new era. In 2020, the European Commission fleshed out the European Green Deal that, while still attempting to square the circle of green growth, represented a change of gear in climate policy-a mechanism to mainstream climate change in multiple spheres of policymaking. At the time of writing, the newly elected US president Joe Biden is signing the country back into the terms of the Paris Agreement. China is pushing ahead with an industrial strategy that puts renewables at the forefront of its econ- omy. However, despite the global attention to climate change, we seem to be losing adaptation and mitigation opportunities, especially in lower-income countries.

The Covid-19 outbreak in 2020 has impacted all economies, but its bearing on the environment is at best ambiguous (International Energy Agency, 2020; Le Quéré et al., 2020). The Covid-19 outbreak has also compromised ongoing efforts to reduce poverty and inequality (World Bank, 2020), and it has generated a need for stimulus packages of which sizeable portions will likely go to infrastructure, to facilitate digital connectivity, health care, pandemic-proofing of public services, and 
mobility (Abadie, 2020). Will these investments change the world's trajectory towards a low carbon, climateresilient future?

Prior to the Covid-19 pandemic, a confluence of emergency declarations, novel engagement activities and social movements were generating momentum for advancing courageous visions of future, low-carbon development. The climate actions discussed in this thematic issue explore whether the changes in climate change rhetoric and diversification of action sites, spaces, and mechanisms that have emerged over the past decade mark a radical shift of direction in the challenge of reducing carbon emissions and ensuring the liveability of the world for future generations.

Questions have roundly focused on how to respond and who will suffer the most (Mann, 2021). Climate change affects human health and wellbeing-with increasing evidence of mental health problems like solastalgia directly linked to climate change (Albrecht et al., 2007; Pihl et al., 2021). While the youth climate movement is increasing awareness of climate change in the public consciousness and re-centering climate debates around intergenerational ethics and justice, the landscape of climate action seems plagued by unintended impacts, as empirical evidence emerges of greening projects' negative impacts, for example, causing people's displacement (UN-Habitat, 2020). A just transition requires something other than incremental improvements on infrastructure and services: It requires a cultural shift that helps to reimagine human life within the world's confines. Such a cultural shift, however, requires political grounding.

This thematic issue enquires as to whether this 'new politics' of climate change signifies the continuation of business as usual or heralds a radical change in language, approach, and participation. If such a change is detectable, then there is a question of whether such change will lead towards a positive wave of environmental action or towards the creation of new inequalities. The articles in this thematic issue explore various terrains of contemporary climate politics, interrogating the extent to which they are reflective of a new climate politics marking a radical step change from the climate politics as usual which have failed to move global emissions in the right direction since 1990. Despite their diversity, both geographically and substantively, the articles identify common dimensions: the significance of new discourses of climate action, the creation of new places and spaces for engagement, and the expansion of climate agents with specific attention to previously marginalised voices.

\section{Dimensions of a New Climate Politics}

\subsection{The Significance of Discourses}

When we look at climate change discourses, a key question is the extent to which the proliferation of new terms ('climate emergency,' 'Green New Deal,' 'just transitions') reflect new ways of thinking or are simply a continuation of 'old discourses' of climate politics repackaged in a new context. Samper, Schockling, and Islar (2021), for example, explore this question in the context of the Green New Deal (USA) and Green Deal in the European Union. In their article, the Green (New) Deal emerges as a new set of discourses of green development that are seen as potentially revolutionizing current climate responses both in Europe and North America. The New Deal evokes the public works, social policy and financial reforms that, under President Franklin D. Roosevelt changed the American landscape between 1933 and 1939. The moniker, however, stands uneasily with the diverse set of other narratives that Samper and colleagues review, from programmes for green growth and infrastructure development to those that represent a fundamental criticism of current forms of organisation. The European Green Deal is perhaps the most advanced programme which affects every sector of the economy, from infrastructure development, to labour policy and the circular economy. However, despite the step-change in language and explicitly allocated funds for action, Samper and colleagues find it lacking, reproducing previous discourses and curtailing spaces for political debate.

Adopting a new 'green' discourse, then, does not alone indicate a radical new approach to climate action. This is a refrain reiterated by Ruiz-Campillo, Castán Broto, and Westman (2021) in their examination of the declarations of a climate emergency by 300 local governments in 24 countries. They argue that such declarations respond to growing pressure from social movements in international politics and signify a growing recognition of the sub-national government's role in climate governance (Ruiz-Campillo et al., 2021). However, they also note that framing climate change as an emergency does not, in and of itself, make decisions about which measures to adopt any easier. Nor does it necessarily impact the effectiveness of those measures over time.

Another institutional context-the universityprovides additional opportunities for the emergence of new discourses and O'Neill and Sinden (2021) examine climate emergency declarations made in this context in the UK. Universities potentially present progressive organisations to support the implementation of low carbon futures; however, the research conducted by O'Neill and Sinden (2021) cautions against assuming that such declarations are solely driven by desires to support a radical uptick in climate action. Other concerns around market differentiation, sustainability capital, and competition for students also play a part in universities declaring a climate emergency.

While the declarations constitute performative, positioning exercises providing symbolic recognition of the urgency of the climate change challenge, they do not automatically translate into a radically different response to that challenge. Indeed, Ruiz-Campillo et al. (2021) note that most cities have not adopted plans 
or initiatives under their emergency declarations that go much further than existing plans. Neither do O'Neill and Sinden (2021) reveal any evidence of radical innovation in university declarations. What they do provide is an opportunity for renewing cities' and universities' commitments constituting an anchor to expand dialogue across public, private and civil society arenas.

The ambiguity of emergency discourses is also an underpinning feature of the article by Fitzgerald, Tobin, Burns, and Eckersley (2021) exploring how policy-makers can reset agendas, veto proposals, and dismantle legislation even when a climate emergency has been declared. They identify the need for more expansive conceptual tools to examine the diverse ways policy-makers can work to delay radical climate action, developing the concept of 'policy stifling' to describe how the national government in Ireland issued a climate emergency declaration while also preventing the passage of a substantive Climate Emergency Measures Bill using the 'money message'-a policy tool that allows legislation to be delayed if it has implications for public finances. While Fitzgerald et al. (2021) conclude that the period they analyse between 2016-2020 does represent an era of new climate politics in Ireland, this new climate politics has yet to produce substantive policy developments, and emissions continue to travel in the wrong direction. This issue is revisited by Long (2021) in another context, that of climate finance. Here Long interrogates some of the potential vulnerabilities and injustices that run through the landscape of climate finance, linking back to the global financial crisis of 2007-2009. Long (2021) finds that the network of actors and intermediaries involved in climate finance governance has grown rapidly, and a narrative of climate action has become increasingly mainstream. However, he suggests that hopes of a private sector-led renaissance for a just transition to a decarbonised future may be over-optimistic. The application of the business-as-usual approach to finance raises serious concerns, given the sector's preoccupation with credit ratings, risk assurances and market stability. Certainly, as Long argues, emerging climate finance systems must not be permitted to morph into a new form of neo-colonial control through debt bondage justified by exhortations of a climate emergency. Growing diversity in spaces and places for deliberation of climate politics, including climate finance, provides a hopeful counterbalance to such tendencies.

\subsection{New Spaces and Places of Climate Politics}

New spaces of, and places for, climate change action and engagement-including local governments and universities already addressed above-have proliferated in the 21st century, from citizens' assemblies to public exhibitions. In many cases, these initiatives have strong place-based dimensions already identified as influential in enhancing climate change engagement (Davies \& Hügel, 2021). The significance of place-based action is raised in an article by Creasy, Lane, Owen, Howarth, and van der Horst (2021), which examines Edinburgh's Climate Commission. This Commission is described as an experimental form of urban climate governance that strives to cohere fragmented climate governance at the urban scale and better represent the places whose futures they hope to shape. A key to their success is incorporating a diversity of perspectives to truly shape the city with its citizens rather than for them. However, Creasy et al. (2021) find that, despite the explicitly experimental framing of the Commission, the focus on recruiting high carbon emitting industries and a desire to identify discernible short-term impacts limited its possibilities to embrace new perspectives on a climate-proofed future, which also posed legitimacy risks. Nonetheless, there remain opportunities for such place-based Commissions to work closely with local democratic frameworks. More than just holding the local authority to account, such institutional forms could support innovation, empower stakeholders and extend situated climate knowledge within the city, unlocking new resources and possibilities.

While a relatively longstanding, if infrequent, feature of planning and policy deliberations internationally, citizen assemblies focused on climate change have emerged as high-profile fora for broader public engagement at national and sub-national scales (e.g., Devaney, Torney, Brereton, \& Coleman, 2020). Citizen assemblies have created new spaces for dialogue and discussion, yet little is known about the drivers and hopes for these deliberative mechanisms or what public perceptions they generate. Sandover, Moseley, and Devine-Wright (2021) focus on these two knowledge gaps, examining the Devon Climate Assembly process that began in 2019 following the County's declaration of a climate emergency, paying particular attention to matters of legitimacy, credibility, and utility. They find that while widening participation and expanding local voices in climate debates was a key motivating force behind the Assembly, there were also concerns about the practical challenges of ensuring adequate citizen representation and whether citizens would be willing to consider some of the hard choices required to meet climate commitments. Ultimately, they conclude, in a similar vein to Creasy et al. (2021), with a judgment that the Assembly represents a space of cautious experimentation; at best, a modest example of a new climate politics that only lightly challenges existing landscapes of climate power and politics.

Both climate commissions and citizens' assemblies include formal processes for eliciting participants' views. Yet, other alternative spaces can generate different forms of engagement around climate change. The Carbon Ruins exhibition examined by Stripple, Nikoleris, and Hildingsson (2021) was an explicit attempt to help people imagine themselves as part of low-carbon futures. The exhibition presents its contents-relics from our current carbon age-as a means to allow people to reflect on these objects and their implications for 
climate change with the ultimate goal of bridging the gap between abstract future scenarios and everyday experiences in the present. It provides a tangible, visible means for publics to engage with low-carbon world-building processes in ways that are normally inaccessible to them. That said, it is difficult to track and trace the impacts of such engagements both on those who visit the exhibition and wider stakeholders. The exhibition's impacts will be diffuse and intertwined with other media, education, and policy inputs. Nonetheless, they can be seen as additional, even alternative fora for climate politics to be (re)formed and debated, potentially amongst much more diverse publics than more formal mechanisms. This issue of broadening diversity of participation in climate politics forms the third major theme running through the articles in this thematic issue.

\subsection{Diversity and Difference}

Bringing together a focus on place-based interventions for increasing engagement in climate change adaptation with an explicit desire to bring marginalised voices into climate discussions, Davies and Hügel (2021) outline the process and impacts of a set of interactive workshops which were rolled out with young people attending a school located in a disadvantaged area of inner-city Dublin, Ireland. Such interventions are needed because young people in Ireland currently have limited channels to articulate their views, a finding supported by analyses of climate strikes in Ireland and elsewhere (Davies \& Hügel, 2019). While a spatially and time-delimited exercise, it had positive impacts for increasing participants' knowledge of climate change science and policy processes. Such activities can provide important bedrock on which a greater sense of self-efficacy around future engagement with climate action can be generated.

Attending to youth voices in climate politics is also the focus for Fisher and Nasrin (2021) in their socialnetwork analysis of the youth climate movement in the US and the nationally co-ordinated events they established. The article explores how youth movements have evolved and how participants engaged with other social movements concerned with the climate crisis. Although limited in timescale-so unable to make definitive statements about movement trajectories-Fisher and Nasrin (2021) conclude that suggestions of increasing influence by adult-led climate movements found in the data need to be further traced in the future. Both articles, by Fisher and Nasrin and Davies and Hügel, support arguments for more and better-protected spaces for youth voices to be heard autonomously and explicitly incorporated into broader climate politics.

Social media could be a means for public engagement and participation to change climate politics. Yang and Stoddart (2021) use social-network analysis to examine the climate communication patterns in China via Weibo-a micro-blogging site with over half a billion monthly active users. Their research shows that Weibo has enrolled new publics in climate-change debates. Still, the lack of balanced dialogue and users' tendency to interact with people similar to themselves restrict interactions and homogenize information flows.

Moving to the other end of the age spectrum, Keller and Bornemann (2021) explore the KlimaSeniorinnen Schweiz movement trying to force the Swiss government into greater climate action through legal mechanisms, media, and public debate. Here they find that KlimaSeniorinnen functions as a strategic actor in the Swiss climate context, developing collective action frames around human rights and the vulnerabilities of older women to intense heatwaves predicted to increase in frequency and intensity with climate change. Far from focusing only on the specific needs of the elderly in a climate-changed world, KlimaSeniorinnen has also sought to bridge generations, promoting intergenerational justice and flagging responsibilities towards future generations.

In contrast, Kenis (2021), in her analysis of the School Strikes for Climate in Belgium, shows how the establishment of an intergenerational conflict line succeeded initially in raising young people's agenda over an extended period. Young participants accused previous generations of undermining their futures, casting themselves as future climate-change victims. However, this conflict line also fostered change. The movement declined as a post-political consensus imposed technocratic and market-oriented responses to climate change. Kenis (2021) argues, along the same lines as Davies and Hügel (2021), building and maintaining a critical and politicized movement around climate change requires connecting it to other struggles with an emancipatory and intersectional lens.

While the articles in this thematic issue cover a range of settings, spaces, and mechanisms, they do not represent the full range of activities, actors, and institutions emerging around climate change. There is no coverage of vast swathes of the earth in areas collectively and problematically termed the global south. The issue of 'absence' around the discourse of climate emergency in these territories is increasingly recognized (Ruiz-Campillo et al., 2021). There remains an imbalance between widely researched areas and those largely ignored (Hügel \& Davies, 2020). Reports like the Intergovernmental Panel on Climate Change (IPCC) struggle to obtain balanced evidence about, for example, how to respond to climate emergencies in countries for which there is little data or information of any kind. Climate politics is not an exception. That climate politics in the global south are not widely studied or researched does not mean that there are no politics in those areas. For example, in January 2020, Ugandan youth activist Vanessa Nakate was cropped out of a photo with Greta Thunberg. The outrage pointed both at the exclusion of brown and black people from narratives of climate change impact and the lack of acknowledgment of the rise of youth activism in African countries. 
Another issue where further substantive work is required is the relative dislocation of climate change politics from broader accounts of structural inequalities (Davies, Hooks, Knox-Hayes, \& Liévanos, 2020). Some of the articles in this thematic issue, such as Long's, point towards the racist, colonialist roots of the climate emergency. Fisher and Nasrin also link youth climate activism with the Black Lives Matter movement. However, although some studies link antiracist politics to climate action, they are still few and far between. The construction of environmentalism as white both denies the historical development of environmentalism and its present potential. We cannot understand the environmental movement without understanding its links to antiracist activism and the links to the civil rights movement in the US (Agyeman, Schlosberg, Craven, \& Matthews, 2016).

\section{Conclusion: A Research Agenda for a 'New Climate Politics'}

The Paris Agreement of 2015, with its legally-binding commitment to limit global heating and the subsequent adoption of the Global Climate Action Agenda, set the stage for a wide-ranging reconfiguration of climate change politics. Five years after its adoption, it is clear that the agreement is driving climate action, but has it resulted in a 'new politics'? As Hale points out, several conditions must be met "in order for societies to benefit from a positive use of political power over a sustained period" (2010, p. 256; Mulgan, 2007): an "active civil society; a favourable world order; ethical leadership, and a culture of learning in government."

What will be the result of young people's increasing engagement in climate politics? Resistance to extending the franchise in national elections to 16 -year-olds in the UK and Ireland can be seen as a reaction to this. It is an open question whether there are mechanisms by which climate strikes and street protests will influence policy via the ballot box. More research will be needed to ascertain whether a relationship exists between youth activism and political change and disentangle it from other effects.

Top-down large-scale mobilisation need not be the only manifestation of these new politics: One emerging area of thought which indirectly informs some of the arguments in this collection (e.g., Ruiz-Campillo et al., 2021; Stripple et al., 2021) is the area that focuses on thinking through a politics of the minor, the kind of micropolitical ideas that mobilise Foucault's notions of capillary power into the accidental context of environmental and climate decision-making. Emily Apter (2018) calls these politics 'unexceptional politics,' a politics 'behind the scenes' that mobilise the multi-layered spaces of decision making. So, while we do not see full evidence of a new climate politics, are we looking into the complexities of unexceptional politics? For example, what kinds of unexceptional politics are being mobi- lized in exhibitions to imagine alternative futures, such as Carbon Ruins (Stripple et al., 2021) or in social media (Yang \& Stoddart, 2021)? What is the potential for traditional spaces of power such as legal courts or investor forums to transform (see Keller \& Bornemann, 2021; Long, 2021)?

The Covid-19 emergency has in some ways shown the differences between the climate emergency and the pandemic. In the light of the pandemic and the need for a response, climate concerns have been displaced to the background. Covid-19 has generated new concerns-not only in responding to stop the spread of the virus and alleviating the impacts of lockdown but also in terms of long-term thinking about the kind of social investments we want to make. In line with the global health emergency that has arisen, it is also worth considering the climate emergency in temporal terms: An emergency requires extraordinary mobilisation of resources and sacrifice at various scales from the personal to the international, and it is often accompanied by the temporary suspension of activities and even rights which are otherwise taken for granted. These restrictions are accepted because they are seen as necessary and, crucially, temporary by a majority of the population. Still, as the pandemic has continued, fatigue has set in even as the world has begun to find ways out of it. What then would allow the climate emergency to be declared at an end? As Hulme points out (2019), net-zero carbon emissions are an unhelpfully narrow policy goal which are at once both insufficiently ambitious and serve to crowd out other concerns, and suggests that a focus on the Sustainable Development Goals (SDGs) is preferable. Future research should focus on the effects of this 'permanent emergency' on people's perceptions of climate change and what is being done to mitigate and adapt to it.

For many, responding to public health concerns goes hand in hand with concerns about climate change. What is certain is that a new landscape of investment and recovery has opened up at the same time as the pandemic has changed our expectations of who we are. As we hope for a post-Covid-19 world, we ask ourselves whether recovery from the pandemic can be a green one. For the sake of people and planet it must only be a green one!

\section{Acknowledgments}

This project has received funding from the European Union's Horizon 2020 research and innovation program under the Marie Skłodowska-Curie grant agreement No. 713567, the financial support of Science Foundation Ireland (SFI) under Grant Number 13/RC/2077 and $16 / \mathrm{SP} / 3804$, and the support from the European Research Council (ERC) under the European Union's Horizon 2020 research and innovation programme Grant Agreement No 804051-LO-ACT-ERC-2018-STG. 


\section{Conflict of Interests}

The authors declare no conflict of interests.

\section{References}

Abadie, R. (2020, May 15). Covid-19 and infrastructure: A very tricky opportunity. World Bank Blogs. Retrieved from https://blogs.worldbank.org/ppps/covid-19and-infrastructure-very-tricky-opportunity

Agyeman, J., Schlosberg, D., Craven, L., \& Matthews, C. (2016). Trends and directions in environmental justice: From inequity to everyday life, community, and just sustainabilities. Annual Review of Environment and Resources, 41, 321-340.

Albrecht, G., Sartore, G.-M., Connor, L., Higginbotham, N., Freeman, S., Kelly, B., . . . Pollard, G. (2007). Solastalgia: The distress caused by environmental change. Australasian Psychiatry, 15(1, Suppl.), S95-S98. https://doi.org/10.1080/103985607017 01288

Apter, E. S. (2018). Unexceptional politics: On obstruction, impasse, and the impolitic. London: Verso.

Creasy, A., Lane, M., Owen, A., Howarth, C., \& van der Horst, D. (2021). Representing 'place': City climate commissions and the institutionalisation of experimental governance in Edinburgh. Politics and Governance, 9(2), 64-75.

Davies, A., Hooks, G., Knox-Hayes, J., \& Liévanos, R. S. (2020) Riskscapes and the socio-spatial challenges of climate action. Cambridge Journal of Regions, Economy and Society, 13(2), 197-213.

Davies, A., \& Hügel, S. (2019, December 4). We asked young people why they're on climate strike. Here's what they said. RTÉ Brainstorm. Retrieved from https://www.rte.ie/brainstorm/2019/1204/ 1097205-we-asked-young-people-why-theyre-onclimate-strike-heres-why

Davies, A. R., \& Hügel, S. (2021). Just adapt: Engaging disadvantaged young people in planning for climate adaptation. Politics and Governance, 9(2), 100-111.

Devaney, L., Torney, D., Brereton, P., \& Coleman, M. (2020). Deepening public engagement on climate change: Lessons from the citizens' assembly (Report No. 314). Wexford: Environmental Protection Agency. Retrieved from https://www.epa.ie/researchand education/research/researchpublications/research reports/research314.html

Fisher, D. R., \& Nasrin, S. (2021). Shifting coalitions within the youth climate movement in the US. Politics and Governance, 9(2), 112-123.

Fitzgerald, L., Tobin, P., Burns, C., \& Eckersley, P. (2021). The 'stifling' of new climate politics in Ireland. Politics and Governance, 9(2), 41-50.

Hale, S. (2010). The new politics of climate change: Why we are failing and how we will succeed. Environmental Politics, 19(2), 255-275. https://doi.org/10.1080/ 09644010903576900
Hügel, S., \& Davies, A. R. (2020). Public participation, engagement, and climate change adaptation: A review of the research literature. WIREs Climate Change, 11(4). https://doi.org/10.1002/wcc.645

Hulme, M. (2019). Climate emergency politics is dangerous. Issues in Science and Technology, 36(1), 23-25.

International Energy Agency. (2020). Global energy review: CO2 emissions in 2020. Paris: International Energy Agency. https://www.iea.org/articles/globalenergy-review-co2-emissions-in-2020

Keller, S., \& Bornemann, B. (2021). New climate activism between politics and law: Analyzing the strategy of the KlimaSeniorinnen Schweiz. Politics and Governance, 9(2), 124-134.

Kenis, A. (2021). Clashing tactics, clashing generations: The politics of the school strikes for climate in Belgium. Politics and Governance, 9(2), 135-145.

Le Quéré, C., Jackson, R. B., Jones, M. W., Smith, A. J. P., Abernethy, S., Andrew, R. M., . . . Peters, G. P. (2020). Temporary reduction in daily global CO2 emissions during the Covid-19 forced confinement. Nature Climate Change, 10(7), 647-653. https://doi. org/10.1038/s41558-020-0797-x

Long, J. (2021). Crisis capitalism and climate finance: The framing, monetizing, and orchestration of resilienceamidst-crisis. Politics and Governance, 9(2), 51-63.

Mann, M. (2021). The new climate war: The fight to take back our planet. New York, NY: Public Affairs.

Mulgan, G. (2007). Good and bad power: The ideals and betrayals of government. London: Penguin.

O'Neill, K., \& Sinden, C. (2021). Universities, sustainability, and neoliberalism: Contradictions of the climate emergency declarations. Politics and Governance, 9(2), 29-40.

Pihl, E., Alfredsson, E., Bengtsson, M., Bowen, K. J., Broto, V. C., Chou, K. T., . . Zelinka, M. (2021). Ten new insights in climate science $2020-\mathrm{A}$ horizon scan. Global Sustainability, 4. https://doi.org/10.1017/sus. 2021.2

Ruiz-Campillo, X., Castán Broto, V., \& Westman, L. (2021). Motivations and intended outcomes in local governments' declarations of climate emergency. Politics and Governance, 9(2), 17-28.

Samper, J. A., Schockling, A., \& Islar, M. (2021). Climate politics in green deals: Exposing the political frontiers of the European Green Deal. Politics and Governance, 9(2), 8-16.

Sandover, R., Moseley, A., \& Devine-Wright, P. (2021). Contrasting views of citizens' assemblies: Stakeholder perceptions of public deliberation on climate change. Politics and Governance, 9(2), 76-86.

Stripple, J., Nikoleris, A., \& Hildingsson, R. (2021). Carbon ruins: Engaging with post-fossil transitions through participatory world-building. Politics and Governance, 9(2), 87-99.

UN-Habitat. (2020). World cities report 2020: The value of sustainable urbanization. Nairobi: UN-Habitat. Retrieved from https://unhabitat.org/World\%20 
Cities\%20Report\%202020

World Bank. (2020). Poverty and shared prosperity 2020: Reversals of fortune. Washington, DC: World Bank. https://doi.org/10.1596/978-1-4648-1602-4
Yang, Y., \& Stoddart, C. J. (2021). Public engagement in climate communication on China's Weibo: Network structure and information flows. Politics and Governance, 9(2), 146-158.

\section{About the Authors}
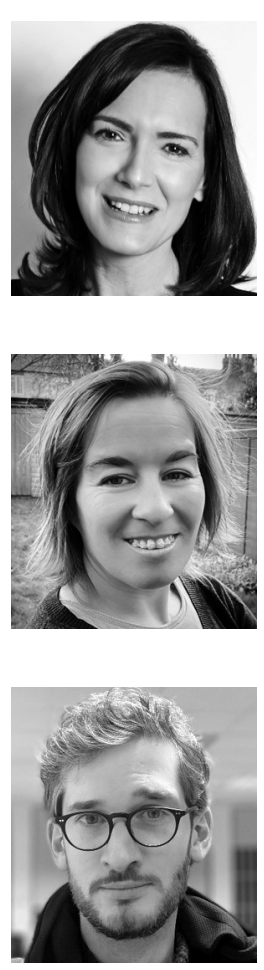

Anna R. Davies is Professor and Chair of Geography, Environment and Society at Trinity College Dublin. She is Director of the Environmental Governance Research Group and a member of the Future Cities Research Centre at Trinity.

Vanesa Castán Broto is Professor of Climate Urbanism at the Urban Institute in the University of Sheffield. Her work focuses on the everyday politics of climate change in cities and communities and she believes that innovative responses to climate change emerge in unexpected places.

Stephan Hügel is a Marie Skłodowska-Curie Research Fellow at Trinity College Dublin. His research interests include smart cities, urban informatics, citizen engagement, and climate change. 